\title{
Impact of community-based educational intervention on breast cancer and its screening awareness among Arab women in the United Arab Emirates
}

\author{
Syed Arman Rabbani ${ }^{\mathrm{a}, *}$, Alyazya Mohammed Salem Khalaf Al Marzooqi ${ }^{\mathrm{b}}$, \\ Abrar Emad Mousa Srouji ${ }^{a}$, Eman Ahmad Hamad ${ }^{\mathrm{c}}$, Asiya Mahtab ${ }^{\mathrm{d}}$ \\ ${ }^{a}$ RAK College of Pharmaceutical Sciences, RAK Medical \& Health Sciences University, Ras Al Khaimah, United Arab Emirates \\ ${ }^{\mathrm{b}}$ Sheikh Khalifa Specialty Hospital, Ras Al Khaimah, United Arab Emirates \\ ${ }^{\mathrm{c}}$ New Medical Center Specialty Hospital, United Arab Emirates \\ ${ }^{\mathrm{d}}$ School of Pharmaceutical Sciences, Jamia Hamdard University, India
}

\section{A R T I C L E I N F O}

\section{Keywords:}

Breast cancer

Awareness

Community-based educational intervention

Early detection

United Arab Emirates

\begin{abstract}
A B S T R A C T
Objectives: Breast cancer (BC) is the most common cancer in women worldwide as well as in United Arab Emirates (UAE). Improving awareness is an important aspect of BC control. Our study explored whether a community-based educational intervention was an effective approach for improving the awareness of BC and its screening procedures and promoting health behavior change.

Methods: The study was carried out as a pre-post-test design among 250 Arab women. Baseline awareness (preintervention) regarding $\mathrm{BC}$ and its screening procedures was assessed using a validated structured questionnaire adapted from the Breast Module of Cancer Awareness Measure. Educational intervention on BC was administered after baseline knowledge assessment. The impact of this intervention was evaluated through the postintervention questionnaire after four weeks.

Results: Statistically significant improvement was observed in all the BC knowledge domains after the educational intervention. Highest percentage change in knowledge (56.4\%) between pre- and post-intervention was seen for BC risk factors. Stratified analyses revealed that the intervention proved more beneficial to the women with no formal education as compared to those with formal education (mean difference: $7.27 \pm 5.29$; $\mathrm{p}=0.001$ ). Post-intervention the women were more positive towards medical help-seeking and acknowledged the fact that BC diagnosed early is more treatable (\% change: $24.0, \mathrm{p}<0.001$ ).

Conclusion: The community-based educational intervention, aimed at improving the knowledge of Arab women towards BC, proved to be effective in raising awareness of the study population. Further efforts are required to ascertain that this augmented awareness is retained in the long term and translated into required health behavior changes.
\end{abstract}

\section{Introduction}

Cancer is a leading cause of death globally, resulting in an estimated 9.6 million deaths in 2018. ${ }^{1}$ Breast cancer (BC) remains the most common cancer in women with 2.09 million cases this year. ${ }^{2}$ As per the latest report of International Agency for Research on Cancer, BC topped the total 4707 new cancer cases in United Arab Emirates (UAE) in 2018. ${ }^{3}$ The average age of women in UAE at presentation of BC is a decade younger than in western countries. ${ }^{4-6} \mathrm{BC}$ presenting at a younger age has more aggressive clinical behavior and poorer prognosis. Early detection of BC can improve outcomes and survival. BC screening plays a critical role in early detection of the disease and thereby reducing the related morbidity and mortality. ${ }^{7}$

In UAE, the Ministry of Health and Prevention has made colossal efforts to promote early detection of $\mathrm{BC}$ and is the key provider of various $\mathrm{BC}$ screening programs at the national level. ${ }^{8}$ These screening programs are in line with the international recommendations for age of onset and the frequency of BC screening. ${ }^{79}$ For UAE national women above the age of 40 years the BC screening services are free of charge and widely available. ${ }^{10}$

However, despite of efforts from government and non-government organizations, women participation in screening programs is not encouraging. Many barriers like lack of knowledge and awareness about $\mathrm{BC}$, limited access to information on BC screening programs, socio-

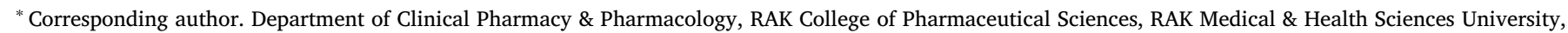
Ras Al Khaimah, United Arab Emirates.

E-mail address: arman@rakmhsu.ac.ae (S.A. Rabbani). 
cultural and traditional beliefs and personal fears are responsible for this under-utilization of screening services. ${ }^{11-13}$ Studies have shown that women who are more knowledgeable about BC and benefits of screening are more likely to participate in screening programs. ${ }^{14,15}$ Educational interventions have proven to be effective in increasing the knowledge of $\mathrm{BC}$ and practice of breast self-examination. ${ }^{16-19}$

Very few studies have been conducted in UAE assessing the knowledge of BC and its screening in the Arab women. ${ }^{14,20,21}$ These studies reported lack of awareness regarding BC among these women and emphasized on the urgent need of community educational interventions to raise the awareness and knowledge of $\mathrm{BC}$ and its screening procedures.

We therefore, conducted this study to assess the knowledge of Arab women regarding $\mathrm{BC}$ and its screening and to investigate the impact of a community-based educational intervention on the same.

\section{Methods}

\subsection{Study design and sample population}

The study was conducted through a one-group pretest-posttest experimental design in the northern emirate of Ras al Khaimah (RAK), UAE. In this design the same group of participants were administered the intervention and their pre- and post-test scores were compared. All adult females living in the study setting were considered for the study. Convenience sampling technique was used to recruit the study participants. Two hundred and sixty eight women agreed to participate in the study and gave written informed consent. Eighteen women were excluded from the study as they presented with history of BC. A total of 250 women were included in the study and considered for data analysis.

\subsection{Study instrument}

A cross-sectional face-to-face survey using a structured questionnaire adapted from the Breast Module of Cancer Awareness Measure (Breast-CAM ${ }^{22}$ was used to assess the impact of educational intervention on $\mathrm{BC}$ awareness. The questionnaire was also translated into Arabic language with the help of an expert in linguistics.

\subsection{Validity and reliability of study instrument}

Study questionnaire was adapted from Breast-CAM which is a valid and reliable tool for assessing the BC awareness. The content validity of our study questionnaire was further determined by a panel of experts. All recommended modifications were done according to the experts' feedback on clarity of sentences and the appropriateness of the content. The questionnaire was pretested on 10 women before the conduct of the study. The field testing of the questionnaire yielded a Cronbach's alpha reliability score of 0.90 , indicating high-internal reliability.

The adapted questionnaire consisted of 9 domains with a total of 36 questions: domain 1 was about the sociodemographic characteristics of the participants (5-item), domain 2 assessed general knowledge of BC (3-item), domain 3 measured knowledge of BC symptoms (6-item), domain 4 was for assessing knowledge of age-related and lifetime risks of BC (2-item), domain 5 was for knowledge of BC risk factors (8-item), domain 6 assessed awareness of the participants towards BC screening (4-item), domain 7 was for knowledge of BC treatment (2-item), domain 8 evaluated confidence, skills and behavior in relation to breast changes (2-items) and domain 9 was related to the barriers to seeking medical help (4-items).

\subsection{Educational intervention}

The educational intervention consisted of a session of about $45 \mathrm{~min}$. In addition to this slide show and handouts were used as educational resources. The content of the session included general information on BC, BC epidemiology, breast anatomy, BC risk factors, signs and symptoms, importance of early detection, screening procedures, breast self-examination (BSE) and mammography, role of BSE and mammography in early diagnosis of $\mathrm{BC}$ and treatment options for BC.

\subsection{Data collection procedure}

Participants were enrolled in the study based on the study criteria and were required to give a written informed consent after reading the participant information sheet designed for the study before enrollment. Baseline knowledge (pre-test) regarding $\mathrm{BC}$ was assessed using the study questionnaire. Educational intervention on $\mathrm{BC}$ was administered after the baseline knowledge assessment. The impact of this intervention was evaluated with the help of post-test questionnaire after four weeks.

\subsection{Data analysis}

Data collected during the study period was analyzed using the Statistical Package for the Social Sciences (SPSS) version 22.0. Pearson $\chi^{2}$ test was used for establishing relationship between the categorical variables. The differences in the mean score between pre- and postintervention were tested using ANOVA. Pre- and post-educational intervention BC awareness change was analyzed by McNemar's test. $\mathrm{P} \leq 0.05$ were considered statistically significant.

\subsection{Ethical considerations}

Ethical approval was taken from RAK Medical and Health Sciences University Research and Ethics Committee (RAKMHSU-REC-12-2017UG-P) and Ministry of Health and Prevention Research and Ethics Committee (MOHP/RAK/SUBC/NO:38-2017-UG-P) prior to the initiation of the study.

\section{Results}

\subsection{Socio-demographic characteristics}

All the 250 women included in the study completed their pre-test and post-test questionnaires. The mean age of the participants was $27.6 \pm 10.8$ years, with age ranging from 18 to 65 years. Majority of the study respondents $(59.2 \%, 95 \%$ CI: $53.2-65.6)$ were in the age group of $18-24$ years, were single (66.4\%, $95 \%$ CI: $60.4-72.4)$, had no family history of BC $(72.0 \%$, 95\% CI: $66.4-77.6)$ and had received graduation level and above education (68.0\%, 95\% CI: 62.0-73.6). Table 1 shows the socio-demographic characteristics of the study participants.

\subsection{Impact of educational intervention}

The mean knowledge score of the study participants was $12.9 \pm 5.9$ before the educational intervention which increased significantly to $19.3 \pm 1.9$ after the intervention.

Significant improvement was observed in all the BC knowledge domains from pre-to post-intervention. Table 2 and Fig. 1 depict the comparison of pre- and post-intervention awareness of $\mathrm{BC}$ and its screening.

\subsubsection{Breast cancer risk factor awareness}

Highest percentage change in knowledge $(56.4 \%)$ between pre- and post-intervention was seen for $\mathrm{BC}$ risk factors domain. Recognition of past history of $\mathrm{BC}$ (\% increase: $22.8 ; \mathrm{p}=0.002)$, use of hormone replacement therapy (\% increase: $46.4 ; \mathrm{p}<0.001$ ), being overweight $(\%$ increase: $63.2 ; \mathrm{p}<0.001$ ), a first degree relative with BC (\% increase: 27.2; $\mathrm{p}<0.001$ ), having children later on in life (\% increase: 66.8; 
Table 1

Socio-demographic characteristics of the study participants.

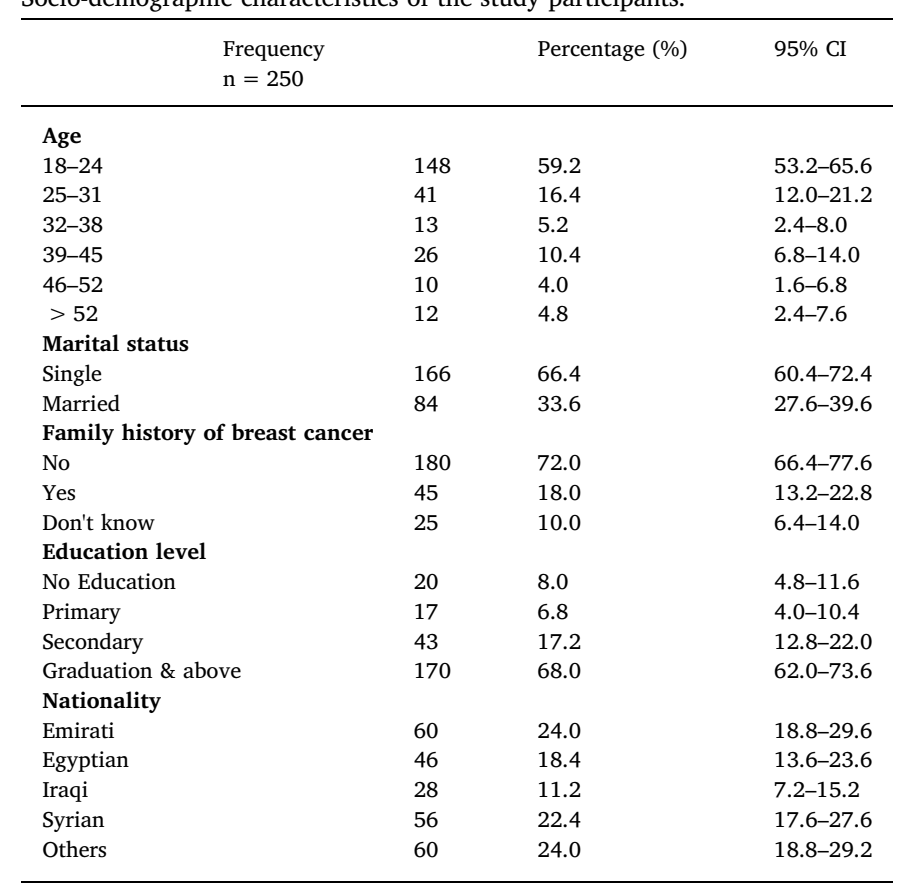

$\mathrm{p}<0.001$ ), periods at an early age ( $\%$ increase: 78.4; $\mathrm{p}<0.001$ ), late menopause (\% increase: 72.8; $\mathrm{p}<0.001)$ as risk factors increased significantly after the intervention.

\subsubsection{Breast cancer symptoms and screening awareness}

Awareness of BC signs and symptoms also improved significantly after the administration of educational intervention to the study participants. The percentage increase in correct answers ranged from $22.4 \%$ for changes in shape/size of breast/nipple to $49.6 \%$ for redness of breast skin, with highly significant differences $(\mathrm{p}<0.001)$. A

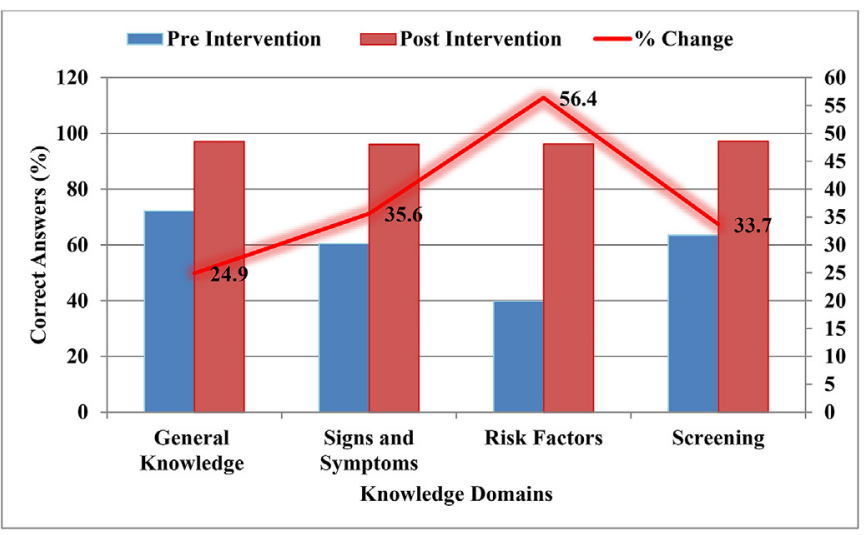

Fig. 1. Pre- and post-intervention knowledge of study participants regarding breast cancer and its screening as per different domains.

significant increase was seen in women's knowledge of BC screening after the educational intervention. Recognition of BSE (\% increase: 16.0; $\mathrm{p}=0.002$ ) and mammography (\% increase: 44.4; $<<0.001)$ as tools for early detection of BC significantly improved after the intervention.

3.2.3. Association of breast cancer awareness with socio-demographic characteristics

Stratified analyses were carried out for the mean BC knowledge scores as per the sociodemographic variables of the study participants including age, nationality, marital status, education level and family history of BC (Table 3).

Women across different age groups displayed improvement in knowledge score after the educational intervention. Furthermore, women in the age group (39-45 years) had a higher mean difference $(7.03 \pm 5.63)$ than the other groups but these results could not reach statistical significance.

The analyses revealed that there was a statistically significant association between the education level of the study participants and the

Table 2

Comparison of pre- and post-intervention breast cancer awareness.

\begin{tabular}{|c|c|c|c|c|}
\hline \multirow[t]{2}{*}{ Knowledge item } & \multicolumn{2}{|c|}{ Correct answers (\%) } & \multirow[t]{2}{*}{ Percent of change } & \multirow{2}{*}{$\begin{array}{l}\text { Mc-Nemar test } \\
\text { P value }\end{array}$} \\
\hline & $\begin{array}{l}\text { Pre-test } \\
\mathrm{n}=250\end{array}$ & $\begin{array}{l}\text { Post-test } \\
\mathrm{n}=250\end{array}$ & & \\
\hline \multicolumn{5}{|l|}{ General knowledge of breast cancer } \\
\hline Breast cancer is the most common cancer affecting women & 88.8 & 98.8 & 10.0 & 0.004 \\
\hline All women irrespective of age are at risk of developing breast cancer & 74.0 & 97.2 & 23.2 & $<0.001$ \\
\hline Both women and men can develop breast cancer & 53.6 & 95.2 & 41.6 & $<0.001$ \\
\hline \multicolumn{5}{|l|}{ Knowledge of signs and symptoms } \\
\hline Changes in the shape/size of the breast or nipple could be signs of breast cancer & 75.2 & 97.6 & 22.4 & $<0.001$ \\
\hline Pain in one of the breasts or armpit could be a sign of breast cancer & 67.2 & 96.8 & 29.6 & $<0.001$ \\
\hline Puckering or dimpling of the breast skin could be a sign of breast cancer & 51.2 & 91.6 & 40.4 & 0.004 \\
\hline Bloody discharge from the nipple could be a sign of breast cancer & 55.2 & 97.6 & 42.4 & $<0.001$ \\
\hline Redness of the breast skin could be a sign of breast cancer & 46.0 & 95.6 & 49.6 & 0.006 \\
\hline A lump or thickening under the armpit could be a sign of breast cancer & 67.6 & 97.2 & 29.6 & $<0.001$ \\
\hline \multicolumn{5}{|l|}{ Knowledge of risk factors } \\
\hline Having a past history of breast cancer is a risk factor for breast cancer & 73.2 & 96.0 & 22.8 & 0.002 \\
\hline Using HRT (Hormone Replacement Therapy) for a long time is a risk factor for breast cancer & 51.2 & 97.6 & 46.4 & $<0.001$ \\
\hline Being overweight (BMI over 30) is a risk factor for breast cancer & 34.4 & 97.6 & 63.2 & $<0.001$ \\
\hline Having a first degree relative (mother, daughter, sister) with $\mathrm{BC}$ is a risk factor for breast cancer & 72.0 & 99.2 & 27.2 & $<0.001$ \\
\hline Having children later on in life or not at all is a risk factor for breast cancer & 27.2 & 94.0 & 66.8 & $<0.001$ \\
\hline Starting the periods at an early age is a risk factor for breast cancer & 18.4 & 96.8 & 78.4 & $<0.001$ \\
\hline Having a late menopause is a risk factor for breast cancer & 20.0 & 92.8 & 72.8 & $<0.001$ \\
\hline Doing less than 30 min of moderate physical activity 5 times a week is a risk factor for breast cancer & 22.0 & 95.6 & 73.6 & $<0.001$ \\
\hline \multicolumn{5}{|l|}{ Knowledge of breast cancer screening } \\
\hline Monthly Breast Self-Examination (BSE) can help to detect the breast changes (lumps, thickening) & 82.8 & 98.8 & 16.0 & 0.002 \\
\hline Clinical Breast Examination (CBE) is recommended for females every 1-3 years starting from the age of 25 years & 56.8 & 97.6 & 40.8 & $<0.001$ \\
\hline Mammography is the best screening tool for early detection of breast cancer & 50.8 & 95.2 & 44.4 & $<0.001$ \\
\hline
\end{tabular}


Table 3

Distribution of mean knowledge scores pre- and post-intervention as per socio-demographic characteristics.

\begin{tabular}{|c|c|c|c|c|c|}
\hline \multirow[t]{3}{*}{ Variable } & \multicolumn{4}{|c|}{ Breast cancer knowledge score } & \multirow[t]{3}{*}{ Significance test ${ }^{a}$} \\
\hline & Pre-test & & Post-test & Difference & \\
\hline & Mean \pm SD & & Mean \pm SD & Mean \pm SD & \\
\hline \multicolumn{6}{|l|}{ Age } \\
\hline $18-24$ & $13.02 \pm 6.00$ & & $19.20 \pm 2.18$ & $6.18 \pm 5.67$ & $\mathrm{p}=0.746$ \\
\hline $25-31$ & $13.60 \pm 6.35$ & & $19.80 \pm 0.60$ & $6.19 \pm 6.27$ & \\
\hline $32-38$ & $14.38 \pm 6.64$ & & $19.84 \pm 0.37$ & $5.46 \pm 6.53$ & \\
\hline $39-45$ & $12.30 \pm 4.98$ & & $19.34 \pm 2.41$ & $7.03 \pm 5.63$ & \\
\hline $46-52$ & $12.90 \pm 7.35$ & & $19.00 \pm 1.49$ & $6.10 \pm 7.10$ & \\
\hline$>52$ & $10.41 \pm 4.29$ & & $19.08 \pm 1.72$ & $8.66 \pm 5.43$ & \\
\hline \multicolumn{6}{|l|}{ Nationality } \\
\hline Emirati & & $14.45 \pm 6.38$ & $19.13 \pm 2.39$ & $4.68 \pm 6.12$ & $\mathrm{p}=0.044$ \\
\hline Egyptian & & $11.50 \pm 5.24$ & $19.17 \pm 2.17$ & $7.67 \pm 5.02$ & \\
\hline Iraqi & & $12.50 \pm 6.53$ & $19.03 \pm 2.15$ & $6.53 \pm 5.64$ & \\
\hline Syrian & & $11.89 \pm 5.69$ & $19.35 \pm 2.02$ & $7.46 \pm 5.93$ & \\
\hline Others & & $13.90 \pm 5.76$ & $19.78 \pm 0.45$ & $5.88 \pm 5.83$ & \\
\hline \multicolumn{6}{|l|}{ Marital status } \\
\hline Single & & $12.88 \pm 5.90$ & $19.17 \pm 2.24$ & $6.28 \pm 5.71$ & $\mathrm{p}=0.811$ \\
\hline Married & & $13.17 \pm 6.14$ & $19.65 \pm 1.01$ & $6.47 \pm 6.10$ & \\
\hline \multicolumn{6}{|l|}{ Education level } \\
\hline No Education & & $11.97 \pm 5.87$ & $19.15 \pm 1.53$ & $7.27 \pm 5.29$ & $\mathrm{p}=0.001$ \\
\hline Primary & & $13.52 \pm 5.01$ & $19.29 \pm 2.91$ & $5.76 \pm 6.23$ & \\
\hline Secondary & & $14.00 \pm 6.90$ & $19.79 \pm 0.77$ & $5.75 \pm 6.21$ & \\
\hline Graduation and Above & & $16.27 \pm 5.53$ & $19.24 \pm 2.05$ & $2.96 \pm 6.67$ & \\
\hline \multicolumn{6}{|c|}{ Family history of breast cancer } \\
\hline No & & $12.77 \pm 5.91$ & $19.37 \pm 1.77$ & $6.60 \pm 4.12$ & $\mathrm{p}=0.033$ \\
\hline Yes & & $14.92 \pm 6.71$ & $18.93 \pm 2.81$ & $4.01 \pm 3.92$ & \\
\hline Don't know & & $12.75 \pm 5.72$ & $19.80 \pm 0.50$ & $7.04 \pm 5.20$ & \\
\hline
\end{tabular}

a Testing the difference in breast cancer knowledge score changes, between groups.

improvement in knowledge regarding BC. The results showed that the intervention proved more beneficial to the participants with no formal education as compared to those with formal education (mean difference: $7.27 \pm 5.29 ; p=0.001$ ). The mean differences in knowledge scores of women who were unware of their BC family history and of women with no family history of BC $(7.04 \pm 5.20$ and $6.60 \pm 4.12$ respectively) were significantly higher $(\mathrm{p}=0.033)$ when compared with women with family history of cancer.

\subsubsection{Attitudes towards breast cancer and medical help-seeking}

There was a positive change in the attitude towards visiting a doctor on observing change in the breast ( $\%$ change: $57.6, \mathrm{p}<0.001)$ postintervention. After the intervention the participants were more confident talking about the symptom with the doctor (\% change: -10.8 , $\mathrm{p}=0.036$ ), less embarrassed to go and see the doctor (\% change: $-36.0, \mathrm{p}<0.001$ ) less worried about what the doctor find (\% change: $-14, \mathrm{p}=0.028$ ) and acknowledged the fact that $\mathrm{BC}$ diagnosed early is more treatable (\% change: $24.0, \mathrm{p}<0.001$ ). Table 4 represents preand post-intervention attitudes of the Arab women towards BC and medical help-seeking.

\section{Discussion}

Our study aimed to assess the impact of a community-based educational intervention on improving the awareness of $\mathrm{BC}$ and its screening among the women. To our knowledge, this is the first conducted community-based educational intervention for BC among the Arab women living in the emirate of RAK, UAE. In our study sample, results suggested that following the targeted $\mathrm{BC}$ educational intervention, the Arab women became more aware of BC risk factors and symptoms and demonstrated positive change in the attitude towards $\mathrm{BC}$, its screening procedures and medical help seeking. Focused community-based educational interventions may be a useful addition to the government efforts towards BC prevention and control.

Our study revealed that the overall baseline knowledge of the study population regarding BC and its screening procedures was low. This finding is in line with the results of previous studies conducted in UAE
Table 4

Attitudes towards breast cancer and medical help-seeking.

\begin{tabular}{|c|c|c|c|c|}
\hline & \multicolumn{2}{|c|}{ Response (\%) } & \multirow[t]{2}{*}{ Percent of change } & \multirow{2}{*}{$\begin{array}{l}\text { Mc-Nemar test } \\
\text { P value }\end{array}$} \\
\hline & $\begin{array}{l}\text { Pre-test } \\
\mathrm{n}=250\end{array}$ & $\begin{array}{l}\text { Post-test } \\
\mathrm{n}=250\end{array}$ & & \\
\hline \multicolumn{4}{|c|}{ Checking of breast } & \multirow[t]{5}{*}{$<0.001$} \\
\hline Weekly & 6.0 & 9.2 & 3.2 & \\
\hline Monthly & 9.2 & 42.0 & 32.8 & \\
\hline Once in 6 months & 12.4 & 14.6 & 2.2 & \\
\hline Rarely or Never & 72.4 & 35.2 & -37.2 & \\
\hline \multicolumn{5}{|c|}{ Visit a doctor on observing change in breast } \\
\hline Yes & 12.8 & 70.4 & 57.6 & $<0.001$ \\
\hline \multicolumn{5}{|c|}{ Reasons for not visiting the doctor } \\
\hline \multicolumn{5}{|c|}{ Too embarrassed to go and see the doctor } \\
\hline Yes & 73.2 & 37.2 & -36.0 & $<0.001$ \\
\hline \multicolumn{5}{|c|}{ Too busy to make time to go to the doctor } \\
\hline Yes & 55.6 & 52.4 & -3.2 & 0.039 \\
\hline \multicolumn{5}{|c|}{ Not confident talking about symptom with the doctor } \\
\hline Yes & 51.6 & 40.8 & -10.8 & 0.036 \\
\hline \multicolumn{5}{|c|}{ Worried about what the doctor might find } \\
\hline Yes & 57.6 & 43.6 & -14.0 & 0.028 \\
\hline \multicolumn{5}{|c|}{ Cancer diagnosed early is more treatable } \\
\hline Agree & 74.0 & 98.0 & 24.0 & $<0.001$ \\
\hline
\end{tabular}

which reported lack of awareness about BC and its screening. ${ }^{14,20,21}$ The educational intervention resulted in significant improvement in all the BC knowledge domains. Our findings concur with the results of other BC educational interventions undertaken in different international studies conducted in United States, ${ }^{17}$ United Kingdom, ${ }^{18}$ Colombia, ${ }^{16}$ Egypt, $^{23}$ Iran $^{24}$ and Kenya. ${ }^{25}$

Awareness of BC risk factors improved significantly after the educational intervention. This improvement post intervention in this line with the findings of studies conducted in Egypt ${ }^{23}$ and Colombia. ${ }^{16}$ For risk factors like 'periods at an early age', 'late menopause', 'having children later on in life' and 'being overweight' degree of recognition was particularly high post intervention. Knowledge of BC signs and symptoms also improved significantly after the administration of the intervention to the study participants. Pre-intervention awareness of BC 
symptoms like 'bloody discharge from the nipple', 'puckering or dimpling of the breast skin' and 'redness of the breast skin' was predominantly low which increased considerably post-intervention. This increase in congruent with the results of studies conducted in Kenya ${ }^{25}$ and Egypt, ${ }^{23}$ and incongruent with the findings of a United Kingdom ${ }^{18}$ study where the symptom awareness was unaffected by the intervention.

In UAE, the Ministry of Health and Prevention is putting in immense efforts towards promotion and implementation of screening activities. ${ }^{8}$ The better baseline knowledge regarding BSE is an indicator of the positive impact these activities are having over the Arab women. Significant increase in the awareness of clinical breast examination/ mammography was observed after the intervention which along with good knowledge of BSE will contribute towards the early detection of $\mathrm{BC}$ in the region.

Stratified analyses revealed significant increase in knowledge postintervention across almost all socio-demographic variables. Analysis by education level showed that while women with no formal education background had lower baseline awareness, the intervention was effective in significantly improving BC awareness across all educational levels. One encouraging finding was that the intervention dramatically improved BC knowledge among illiterate participants with poor baseline knowledge when compared with the educated participants. Similar findings were reported by studies conducted in Turkey ${ }^{26}$ and Egypt. ${ }^{27}$

Negative attitude towards BC and barriers to medical help-seeking were reported by a high proportion of Arab women at the baseline. The intervention was successful in bringing a positive change in the attitude of women towards visiting a doctor on observing change in the breast. The intervention also reduced their fears about wasting doctors time, made them more confident talking about the symptom with the doctor, made them feel less embarrassed to go and see the doctor and reassured them about what the doctor might find. The most critical effectiveness of the intervention was that it made the women acknowledge the fact that $\mathrm{BC}$ if diagnosed early is more treatable.

Strengths of our study are community-based nature of the educational intervention, organized educational intervention delivery and information collection. Community-based approach for disease prevention is effective in disseminating information on public health. ${ }^{28}$ Our findings for baseline $\mathrm{BC}$ awareness levels of the study population are consistent with the other studies conducted in UAE. Limitations include pre-post study design (randomized controlled trial is ideal for evaluating interventions), inability to select random sample may have introduced selection bias, results may not be generalized and lack of evidence on long-term impact of the intervention.

Awareness regarding $\mathrm{BC}$ and benefits of screening procedures can play a critical role in taking timely informed decisions and consequently early detection and treatment of BC. Therefore, BC focused educational programs are essential and important for reducing the huge BC burden. Our findings reinforce the importance of focused community-based educational programs where women from diverse sociocultural, economic and educational backgrounds can participate and raise their awareness regarding various public health concerns like BC.

\section{Conclusion}

In conclusion, our results revealed that the awareness of $\mathrm{BC}$ was low among the Arab women living in RAK, a northern emirate in the UAE, particularly with respect to $\mathrm{BC}$ symptoms, risk factors and routine screening procedures. Our community-based educational intervention, aimed at improving the knowledge of the Arab women towards BC, proved to be effective in raising awareness of this study population. Further efforts are required to ascertain that this augmented awareness is retained in the long term and translated into required health behavior changes.

\section{Conflicts of interest}

None declared.

\section{Funding}

This research did not receive any specific grant from funding agencies in the public, commercial, or not-for-profit sectors.

\section{Acknowledgement}

The authors thank Dr. S Gurumadhva Rao, President, RAK Medical and Health Sciences University for his support and encouragement. The authors would also like to thank Dr. Padma GM Rao, Dean and Dr. Sathvik BS, Chairperson, Department of Clinical Pharmacy and Pharmacology, RAK College of Pharmaceutical Sciences for their help and guidance.

\section{References}

1. World Health Organization. Cancer Fact Sheet [Internet]. 2017; 2017. Available from http://www.who.int/mediacentre/factsheets/fs297/en/ Accessed 2018 Dec 16.

2. Globocan. World Cancer Fact Sheet [Internet]. 2018; 2018. Available from: https: gco.iarc.fr/today/data/factsheets/populations/900-world-fact-sheets.pdf Accessed 2018 Dec 15.

3. Globocan. United Arab Emirates Cancer Fact Sheet [Internet]. 2018; 2018. Available from: https://gco.iarc.fr/today/data/factsheets/populations/784-united-arabemirates-fact-sheets.pdf Accessed 2018 Dec 15.

4. Najjar H, Easson A. Age at diagnosis of breast cancer in Arab nations. Int J Surg. 2010;8:448-452.

5. United Arab Emirates Cancer Registry Report [Internet]. 2014; 2014. Available from: http://www.mohap.gov.ae/Files/MOH_OpenData/520/ UAECancerRegistryReport2014_En.pdf Accessed 2018 Dec 17.

6. Al-Shamsi HO, Alrawi S. Breast cancer screening in the United Arab Emirates: is it time to call for a screening at an earlier age? J Cancer Prev Curr Res. 2018;9:123-126.

7. Siu AL. Screening for breast cancer: U.S. Preventive services task force recommendation statement. Ann Intern Med. 2016;164:279.

8. Ministry of Health and Prevention Launches Free Breast Cancer Screening Campaign for Women of All Nationalities - United Arab Emirates [Internet]. 2017; 2017. Available from: http://www.mohap.gov.ae/en/MediaCenter/News/Pages/1780.aspx Accessed 2018 Dec 16.

9. The American College of Obstetricians and Gynecologists. Breast cancer risk assessment and screening in average-risk women. ACOG Pract Bull. 2017;179:1-16.

10. Early Screening for Cancer - Ministry of Health and Prevention - United Arab Emirates [Internet]. [Accessed 2018 Dec 17]. Available from: http://www.mohap. gov.ae/en/services/Pages/241.aspx.

11. Elobaid Y, Aw TC, Lim JNW, Hamid S, Grivna M. Breast cancer presentation delays among Arab and national women in the UAE: a qualitative study. SSM - Popul Heal. 2016;2:155-163.

12. Bowser D, Marqusee H, El Koussa M, Atun R. Health system barriers and enablers to early access to breast cancer screening, detection, and diagnosis: a global analysis applied to the MENA region. Publ Health. 2017;152:58-74.

13. Abdel-Aziz SB, Amin TT, Al-Gadeeb MB, et al. Perceived barriers to breast cancer screening among Saudi women at primary care setting. J Prev Med Hyg 2018;59:E20-E29.

14. Elobaid YE, Aw TC, Grivna M, Nagelkerke N. Breast cancer screening awareness, knowledge, and practice among arab women in the United Arab Emirates: a crosssectional survey. PLoS One. 2014;9:e105783.

15. Salinas JJ, Byrd T, Martin C, et al. Change in breast cancer screening knowledge is associated with change in mammogram intention in Mexican-origin women after an educational intervention. Breast Canc. 2018;12:1-7.

16. Masso-Calderón AM, Meneses-Echávez JF, Correa-Bautista JE, Tovar-Cifuentes A, Alba-Ramírez PA. Charry-ángel CE. Effects of an educational intervention on breast self-examination, breast cancer prevention-related knowledge, and healthy lifestyles in scholars from a low-income area in Bogota, Colombia. $J$ Canc Educ. 2018;33:673-679.

17. Zeinomar N, Moslehi R. The effectiveness of a community-based breast cancer education intervention in the New York state capital region. $J$ Canc Educ. 2013:28:466-473.

18. Smith SG, Osborne K, Tring S, George H, Power E. Evaluating the impact of a community-based cancer awareness roadshow on awareness, attitudes and behaviors. Prev Med (Baltim). 2016:87:138-143.

19. Akhtari-Zavare M, Juni MH, Said SM, Ismail IZ, Latiff LA, Ataollahi Eshkoor S. Result of randomized control trial to increase breast health awareness among young females in Malaysia. BMC Public Health. 2016;16:1-11.

20. Bener A, Alwash R, Miller CJ, Denic S, Dunn EV. Knowledge, attitudes, and practices related to breast cancer screening: a survey of Arabic women. J Canc Educ. 2001;16:215-220.

21. Younis M, Al-Rubaye D, Haddad H, Hammad A, Hijazi M. Knowledge and awarenes of breast cancer among young women in the United Arab Emirates. Adv Breast Cancer 
Res. 2016;5:163-176.

22. Cancer Research UK. Breast Module of the Cancer Awareness Measure (Breast-CAM). King's Coll London Univ Coll London; 2009. Available from: www.cancerresearchuk. org/sites/default/files/health_professional_breast_cam_toolkit_09.02.11.pdf.

23. Mourad H, El Aziz A, Abd HM, Aziz E, Akl OA, Ibrahim HK. Impact of A Health education intervention program about breast cancer among women in a semi-urban area in Alexandria, Egypt. J Egypt Publ Health Assoc. 2009;84:219-243.

24. Rezaeian M, Sharifirad G, Mostafavi F, Moodi M, Abbasi MH. The effects of breast cancer educational intervention on knowledge and health beliefs of women 40 years and older, Isfahan, Iran. J Educ Health Promot. 2014;3:59-64.

25. Kisuya J, Wachira J, Busakhala N, et al. Impact of an educational intervention on breast cancer knowledge in western Kenya. Health Educ Res. 2014;30:786-796.

26. Budakoglu II, Maral I, Ozdemir A, Bumin MA. The effectiveness of training for breast cancer and breast self-examination in women aged 40 and over. J Canc Educ. 2007;22:108-111

27. Kharboush IF, Ismail HM, Kandil AA, et al. Raising the breast health awareness amongst women in an urban slum area in Alexandria, Egypt. Breast Care (Basel). 2011;6:375-379.

28. Pronk NP, Hernandez LM, Lawrence RS. An integrated framework for assessing the value of community-based prevention: a report of the Institute of Medicine. Prev Chronic Dis. 2013;10:1-6. 